Esta obra está sob o direito de Licença Creative Commons Atribuição 4.0 Internacional.

\title{
INOVAÇÃO TECNOLÓGIA EM SISTEMAS DE ABASTECIMENTO DE ÁGUA
}

Carlos Henrique Cintra Monteiro ${ }^{1}$ José Diêdson Alves de Oliveira ${ }^{2}$ Matheus Henrique Alves da Silva ${ }^{3}$ Thamires Pereira de Oliveira ${ }^{4}$ Eduardo Cabral da Silva

\section{RESUMO}

O Brasil é um país rico em recursos hídricos, mas que enfrenta situações desfavoráveis no quesito abastecimento de água. Onde o mesmo não consegue suprir as demandas e assim carece de investimentos e novas tecnologias, afim de tornar o sistema mais eficiente. $O$ presente artigo faz uso da metodologia de revisão bibliográfica do tipo sistemática integrativa, sendo utilizado um total de nove artigos relacionados com o tema, trazendo um referencial que envolve a temática das tecnologias aplicáveis em sistemas de abastecimento de águas com intuito de otimizá-los para melhor gerenciar os recursos hídricos. Com base nos resultados obtidos, foi possível afirmar que há meios para melhorar os sistemas de abastecimento de águas. O emprego do sistema de informação geográfica e dos processos de automatização são exemplos das alternativas para melhor gerenciar esses sistemas.

Palavras-chave: Abastecimento. Tecnologias. Água.

\footnotetext{
${ }^{1}$ carlinhoshcmonteiro@hotmail.com

2jd.diedson150@hotmail.com

3henrique321santos@hotmail.com

${ }^{4}$ thamiscc@hotmail.com

${ }^{5}$ Edcs.cabral@gmail.com
} 


\section{INTRODUÇÃO}

Tendo em vista a situação atual do sistema de abastecimento de água do país e levando em consideração o fato da urgente necessidade de avanços na área, é de suma importância que novas políticas de desenvolvimento sejam criadas juntamente com investimentos tecnológicos que visem suprir as solicitações demandadas.

Várias são as opções e vertentes que podem ser trabalhadas, como por exemplo sistemas de monitoramento e planejamento dos abastecimentos, "águas inteligentes", sistemas de telemetria e monitoramento de vazões entre diversos outros. O que todas tem em comum é o fato de que partem do pressuposto de que há um déficit do que se diz respeito a sua funcionalidade, haja vista que o atual SAA (Sistema de Abastecimento de Água) do país é precário em diversos aspectos, desde qualidade da água disponibilizada quanto até mesmo o próprio abastecimento e como estamos na era da informação e inovações tecnológicas, nada mais justo que usar desse princípio para ajudar no desenvolvimento dessa área. Partindo dessa afirmação, apresentamos no presente artigo meios pelos quais, essas possíveis inovações tecnológicas tragam benefícios para a população.

\section{MÉTODOLOGIA}

O presente trabalho usou a metodologia de revisão bibliográfica do tipo sistemática integrativa, que utilizou buscas nos bancos de dados das bibliotecas virtuais de periódicos CAPES e SciELO, utilizando os descritores Abastecimento de Água, Inovação e Tecnológia associado ao operador booleano and formando a string de busca. Para compor esse artigo, utilizou-se o seguinte critério de inclusão: artigos publicados entre 2015 a 2020, que tivesse em síntese resposta à pergunta norteadora, atendendo a temática do artigo pelos descritores utilizados, abrangendo sua problemática e que fosse em língua portuguesa. Como critério de exclusão: artigos que não contemplasse a temática e fora da faixa de tempo de publicação que foi estabelecida. Foi montado um quadro (ver Quadro 3) com um resumo dos artigos selecionados conforme critérios de inclusão, constando: autor, tema, tipo de busca, data de publicação e conclusão resumida. No Quadro 1, verifica-se os descritores utilizados e a composição do string de busca, e com resultado desse quadro, montou-se o Quadro 2 onde é resumido a quantidade de artigos encontrados nas plataformas de busca utilizadas, mostrando os quantitativos com e sem filtros. 


\section{QUADRO 1 \\ DETALHAMENTO DAS ETAPAS DA REVISÃO SISTEMÁTICA INTEGRATIVA.}

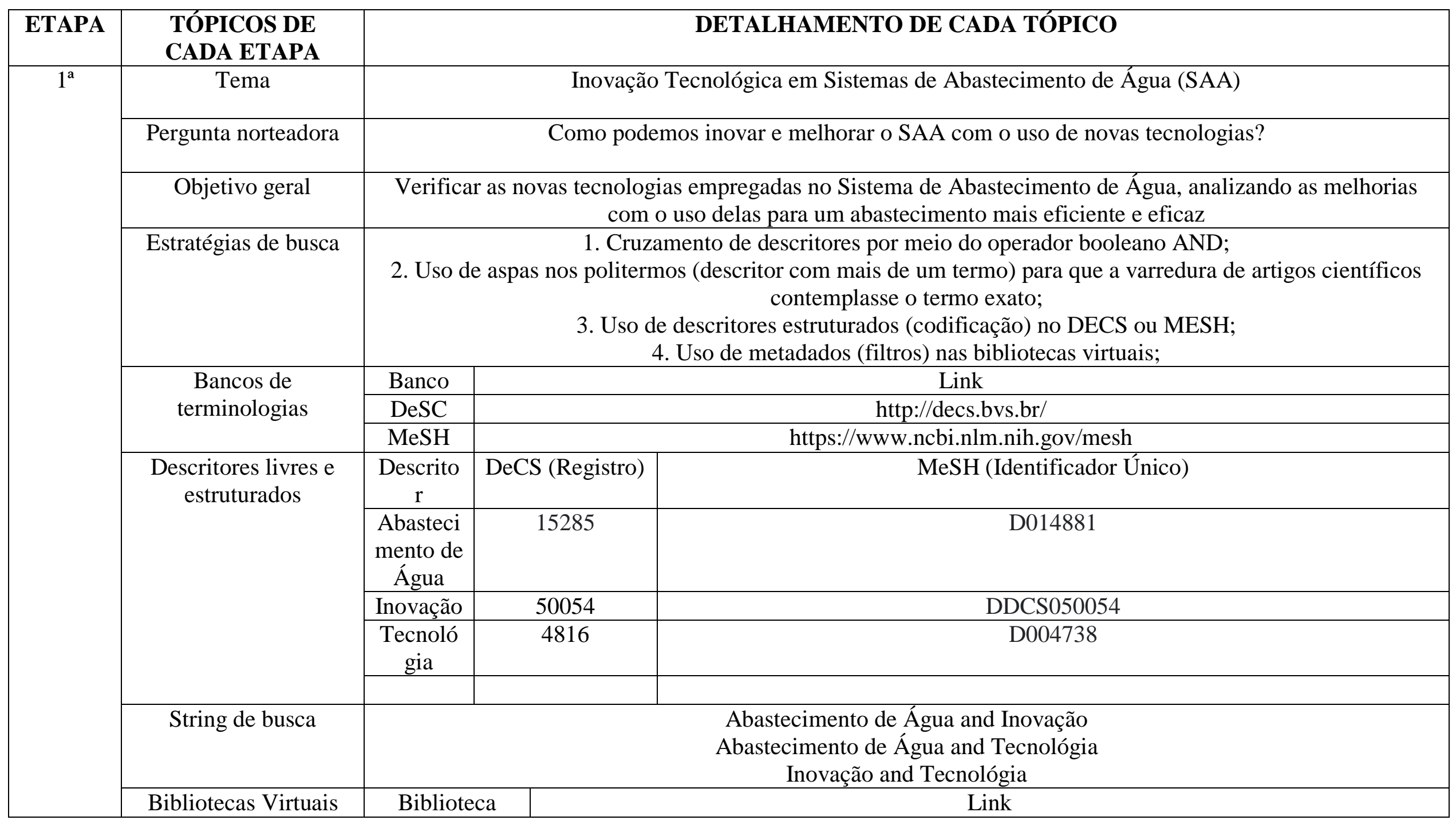




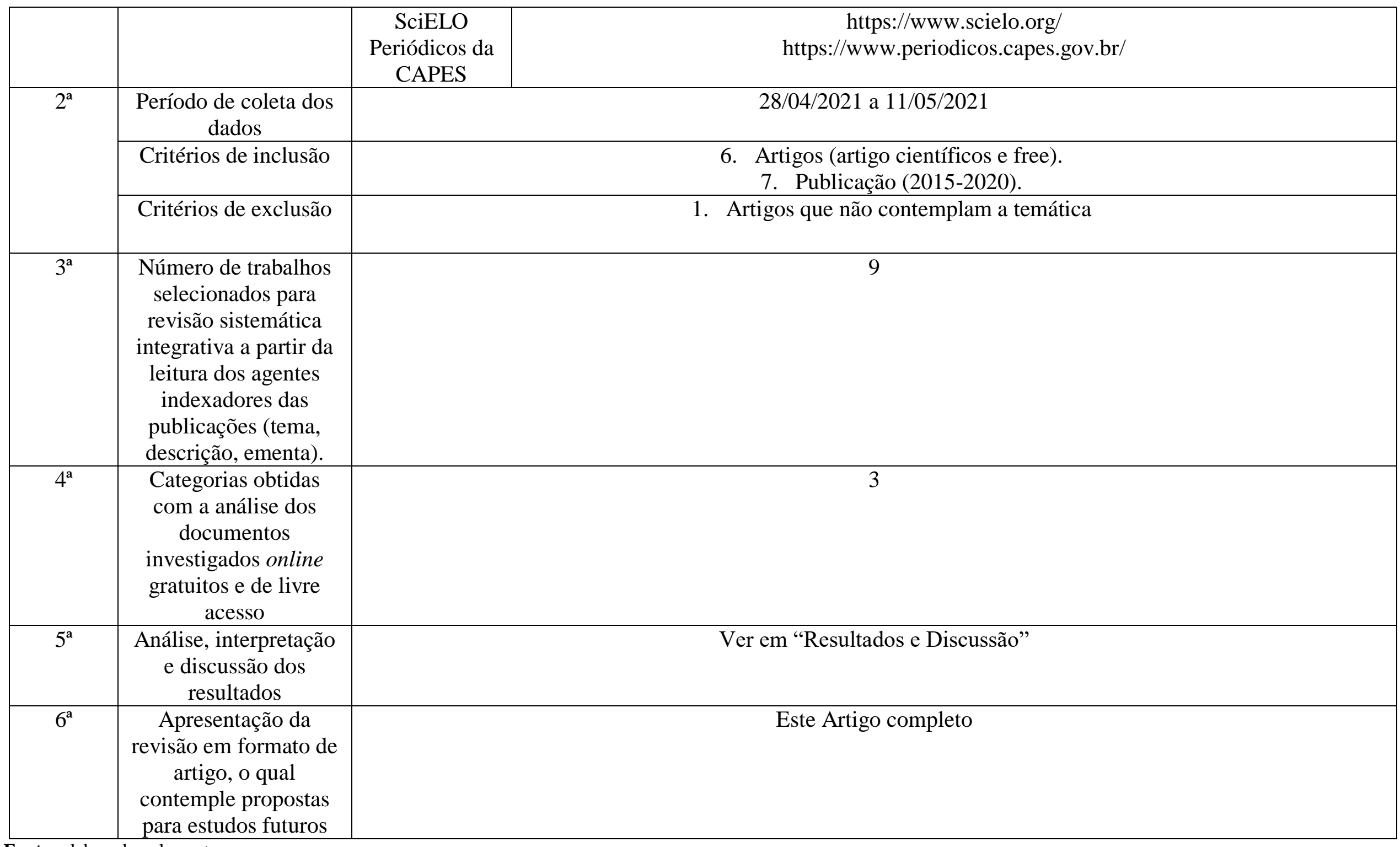

Fonte: elaborada pelos autores. 


\section{RESULTADOS}

\section{QUADRO 2}

CORRESPONDE AO TOTAL DE DOCUMENTOS DISPONÍVEIS NA PLATAFORMA OBTIDOS POR STRING DE BUSCA.

\begin{tabular}{|c|c|c|c|c|}
\hline $\begin{array}{l}\text { String de } \\
\text { busca }\end{array}$ & $\begin{array}{c}\text { Bases de } \\
\text { dados }\end{array}$ & $\begin{array}{c}\text { Total de } \\
\text { publicações } \\
\text { sem o filtro }\end{array}$ & $\begin{array}{c}\text { Publicações } \\
\text { disponíveis } \\
\text { após aplicar os } \\
\text { filtros }\end{array}$ & $\begin{array}{c}\text { Publicações } \\
\text { aproveitadas na } \\
\text { Revisão } \\
\text { Sistemática } \\
\text { Integrativa }\end{array}$ \\
\hline \multirow{2}{*}{$\begin{array}{c}\text { Abastecime } \\
\text { nto de Água } \\
\text { and } \\
\text { Inovação }\end{array}$} & SciELO & 0 & 0 & 0 \\
\hline & $\begin{array}{l}\text { Periódicos da } \\
\text { CAPES }\end{array}$ & 163 & 75 & 1 \\
\hline \multirow{2}{*}{$\begin{array}{c}\text { Abastecime } \\
\text { nto de Água } \\
\text { and } \\
\text { Tecnológia }\end{array}$} & SciELO & 23 & 2 & 2 \\
\hline & $\begin{array}{c}\text { Periódicos da } \\
\text { CAPES }\end{array}$ & 1034 & 303 & 2 \\
\hline \multirow{2}{*}{$\begin{array}{l}\text { Inovação } \\
\text { and } \\
\text { Tecnológia }\end{array}$} & SciELO & 845 & 14 & 0 \\
\hline & $\begin{array}{c}\text { Periódicos da } \\
\text { CAPES }\end{array}$ & 4064 & 69 & 3 \\
\hline
\end{tabular}

Fonte: elaborada pelos autores. 
Quadro 3- Descrição dos documentos (artigos) de acordo com os critérios de inclusão.

\begin{tabular}{|c|c|c|c|c|c|}
\hline $\mathbf{N}^{0}$ & Autor(a) & Tema & Link da publicação & $\begin{array}{c}\text { Data de } \\
\text { publicação }\end{array}$ & Conclusão \\
\hline
\end{tabular}




\begin{tabular}{|c|c|c|c|c|c|}
\hline & & & & & $\begin{array}{l}\text { aproveitamento da água pluvial apresenta-se como uma } \\
\text { alternativa importante para a redução do consumo da água } \\
\text { fornecida pelo sistema público de abastecimento. [...] }\end{array}$ \\
\hline 3 & $\begin{array}{l}\text { Rívea Medri } \\
\text { Borges, } \\
\text { Alessandro } \\
\text { Minillo Eliana } \\
\text { Gertrudes de } \\
\text { Macedo Lemos } \\
\text { Heloiza Ferreira } \\
\text { Alves do Prado } \\
\text { Edson Pereira } \\
\text { Tangerino }\end{array}$ & $\begin{array}{l}\text { Uso de filtros de } \\
\text { carvão ativado } \\
\text { granular associado a } \\
\text { microrganismos para } \\
\text { remoção de fármacos } \\
\text { no tratamento de } \\
\text { água de } \\
\text { abastecimento }\end{array}$ & $\begin{array}{c}\text { https://www.scielo.br } \\
\text { /scielo.php?script=sc } \\
\text { i_arttext\&pid=S1413 } \\
- \\
41522016000400709 \\
\text { \&lang=pt }\end{array}$ & Mar/2016 & $\begin{array}{l}\text { Sobre as condições empregadas no presente estudo, foi } \\
\text { constatada a elevada capacidade de remoção dos compostos } \\
\text { farmacológicos em ambas configurações de filtros testados. A } \\
\text { filtração em carvão ativado, nas condições empregadas neste } \\
\text { estudo, demonstrou ser viável para adsorção e remoção de } \\
\text { fármacos. O carvão ativado mostrou seu potencial como } \\
\text { suporte para o desenvolvimento de microrganismos (biofilme) } \\
\text { capazes de metabolizar os compostos farmacológicos testados, } \\
\text { sua superfície porosa é acessível para fixação e colonização } \\
\text { microbiológica. As bactérias foram predominantes no biofilme } \\
\text { formado no filtro durante o experimento, indicando seu } \\
\text { potencial para compor processos de biofilttração em ETA.[...] }\end{array}$ \\
\hline 4 & $\begin{array}{l}\text { Nathalie Cruz } \\
\text { José Carlos } \\
\text { Mierzwa }\end{array}$ & $\begin{array}{l}\text { Saúde pública e } \\
\text { inovações } \\
\text { tecnológicas para } \\
\text { abastecimento } \\
\text { público }\end{array}$ & $\begin{array}{l}\text { https://scielosp.org/ar } \\
\text { ticle/sausoc/2020.v2 } \\
\text { 9n1/e180824/ }\end{array}$ & $\mathrm{Fev} / 2020$ & $\begin{array}{l}\text { A escassez, a distância e a poluição de mananciais tornam } \\
\text { pouco viável a prática do reuso potável indireto. Os sistemas } \\
\text { de tratamento tradicionais, tanto para águas residuárias como } \\
\text { para água potável, já não são suficientes para promover uma } \\
\text { água segura à população. Por isso, é necessário aprimorar as } \\
\text { tecnologias capazes de remover contaminantes orgânicos, } \\
\text { inorgânicos e organismos patogênicos que os processos } \\
\text { comumente utilizados não são. Em paralelo, a fim de atender à } \\
\text { realidade dos mananciais, é essencial aprimorar instrumentos } \\
\text { legais para monitorar os processos utilizados. [...] }\end{array}$ \\
\hline 5 & $\begin{array}{c}\text { Ceci Queluz } \\
\text { Venturini Paulo } \\
\text { Capel Narvai } \\
\text { Marco Antonio } \\
\text { Manfredini Paulo } \\
\text { Frazão }\end{array}$ & $\begin{array}{c}\text { Vigilância e } \\
\text { monitoramento de } \\
\text { fluoretos em águas de } \\
\text { abastecimento público: } \\
\text { uma revisão } \\
\text { sistemática }\end{array}$ & $\begin{array}{c}\text { https://www.scielo.br } \\
\text { /j/ambiagua/a/6whhJ } \\
\text { dhQwYSXqbCp5QS } \\
\text { zkrB/?lang=pt }\end{array}$ & Dez/2016 & $\begin{array}{l}\text { Os principais fatores intervenientes no estudo de fluoretos em } \\
\text { águas de abastecimento público podem ser agrupados em: } \\
\text { aspectos ligados à área geográfica, incluindo-se o padrão } \\
\text { geológico do solo, o tipo de manancial, o tipo de área (urbana } \\
\text { ou rural), e o grau de desenvolvimento humano; aspectos } \\
\text { concernentes à concessionária, ao tipo de sistema e sua } \\
\text { operação, incluindo características da rede de distribuição; e } \\
\text { aspectos ligados à técnica analítica. A variabilidade dos } \\
\text { estudos quanto ao desenho e aos procedimentos metodológicos } \\
\text { foi elevada. Embora a maioria dos estudos tenha oferecido }\end{array}$ \\
\hline
\end{tabular}




\begin{tabular}{|c|c|c|c|c|c|}
\hline & & & & & $\begin{array}{l}\text { alguma informação sobre a distribuição espaço-temporal das } \\
\text { amostras, em poucos trabalhos foi possível inferir a população } \\
\text { coberta pela fonte de abastecimento investigada. [...] }\end{array}$ \\
\hline 6 & $\begin{array}{l}\text { Renato Leandro } \\
\text { Beregula } \\
\text { Fernanda } \\
\text { Rodrigues da } \\
\text { Silva }\end{array}$ & $\begin{array}{c}\text { Equipamento de } \\
\text { baixo custo para } \\
\text { monitoramento de } \\
\text { pressões em sistemas } \\
\text { de abastecimento de } \\
\text { água }\end{array}$ & $\begin{array}{c}\text { https://www.scielo.br } \\
\text { /j/esa/a/r4qg4ggPj5k } \\
\text { ST3M56nzxQsB/?for } \\
\text { mat=pdf }\end{array}$ & Nov/2020 & $\begin{array}{l}\text { Os dispositivos MPR datalogger, desenvolvidos para a coleta e } \\
\text { o armazenamento das pressões de água monitoradas em } \\
\text { diversas residências, demonstraram-se robustos e precisos, } \\
\text { tendo sido expostos à chuva e ao sol durante os } 43 \text { dias de } \\
\text { coleta de dados sem apresentar nenhum defeito ou } \\
\text { anormalidade, o que corrobora com a possibilidade de } \\
\text { implantação desses dispositivos em redes de abastecimento de } \\
\text { água para o monitoramento das pressões hidráulicas, com } \\
\text { baixo custo para cada dispositivo. [...] }\end{array}$ \\
\hline 7 & $\begin{array}{l}\text { Henrique Gamo } \\
\text { Sonobe } \\
\text { Marta Condé } \\
\text { Lamparelli } \\
\text { Davi Gasparini } \\
\text { Fernandes Cunha }\end{array}$ & $\begin{array}{l}\text { Avaliação espacial e } \\
\text { temporal de aspectos } \\
\text { sanitários de } \\
\text { reservatórios com } \\
\text { captação de água } \\
\text { para abastecimento } \\
\text { em SP com ênfase } \\
\text { em cianobactérias e } \\
\text { cianotoxinas }\end{array}$ & $\begin{array}{c}\text { https://www.scielo.br } \\
\text { /j/esa/a/hDFGqywJ6 } \\
\text { 9WhjZkDpsbJHhr/?f } \\
\text { ormat=pdf }\end{array}$ & Set/2019 & $\begin{array}{l}\text { A análise dos dados permitiu observar que ao menos quatro } \\
\text { dos reservatórios estudados - Itupararanga, Guarapiranga, } \\
\text { Cascata e Billings - apresentaram, no período do estudo } \\
\text { (2011 a 2015), elevadas densidades de cianobactérias. No } \\
\text { entanto, apenas os dois últimos apresentam concentrações de } \\
\text { microcistina preocupantes, acima do valor orientador } \\
\text { recomendado pela Organização Mundial da Saúde (OMS) e } \\
\text { pelo Anexo XX da Portaria de Consolidação no }{ }^{\circ} \text { /GM/MS } \\
\text { (BRASIL, 2017) para água tratada - } 1 \mu \mathrm{g} \text {. L-1. Isso reforça a } \\
\text { necessidade de monitoramento da água tratada e, } \\
\text { eventualmente, de implantação de uma etapa de tratamento } \\
\text { avançado para a remoçãa de cianotoxinas nas suas respectivas } \\
\text { estações de tratamento de água. [...] }\end{array}$ \\
\hline 8 & $\begin{array}{l}\text { João Luiz Boccia } \\
\text { Brandão } \\
\text { Priscila Marcon }\end{array}$ & $\begin{array}{l}\text { SIMCAP: ferramenta } \\
\text { computacional para } \\
\text { auxiliar a tomada de } \\
\text { decisão sobre a } \\
\text { implantação de } \\
\text { sistemas de captação } \\
\text { de águas pluviais }\end{array}$ & $\begin{array}{c}\text { https://www.scielo.br } \\
\text { /j/esa/a/KPxwKSRn8 } \\
\text { hR3h6MRFT4L4xq/ } \\
\text { ?format=pdf }\end{array}$ & Dez/2018 & $\begin{array}{l}\text { A ferramenta SIMCAP foi desenvolvida de forma a gerar } \\
\text { resultados sobre a garantia do abastecimento de um sistema de } \\
\text { captação de água de chuva, a consequente redução do consumo } \\
\text { de água da rede pública e a economia financeira equivalente à } \\
\text { utilização dessa fonte para fins não potáveis. Assim, um dos } \\
\text { principais aspectos positivos da utilização da ferramenta é a } \\
\text { rapidez em se obter informações técnicas e econômicas } \\
\text { relevantes à tomada de decisão. Outro benefício é que sua } \\
\text { formulação pode ser editada por pessoas que saibam utilizar o }\end{array}$ \\
\hline
\end{tabular}

Fonte: elaborada pelos autores. 


\begin{tabular}{|c|c|c|c|c|c|}
\hline & & & & & $\begin{array}{l}\text { software Excel. Dessa forma, além de ser passível de } \\
\text { aprimoramentos, está acessível para uso geral. [...] }\end{array}$ \\
\hline
\end{tabular}


O corpo textual foi analisado por meio da frequência de palavras, que originou a nuvem de palavras (Figura 1) criada na Plataforma online WordArt. Esta ferramenta agrupa e organiza graficamente as palavras-chave evidenciando-as as mais frequentes.

\section{Figura 1 - Gota de palavras}

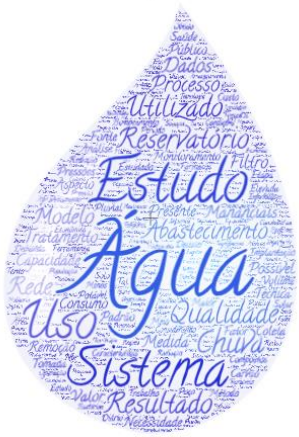

Fonte: elaborada pelos autores.
Por meio da Figura 1, foi possível observar que as palavras em evidência na nuvem pertencem as categorias desenvolvidas a partir da análise de conteúdo de Bardin. Todas as categorias derivam da sua frequência (Tabela 1), que diz respeito ao seu quadro referencial. Em consonância ao objetivo deste trabalho, optou-se por descrever as palavras que apresentaram frequência total no texto e, a partir de seus sentidos nos campos textuais, tinham maior relevância para as inovações tecnológicas em sistema de abastecimento de água, como apresentado na Figura1.

Tabela 1.

Frequência das palavras presentes nos textos publicados nas Plataformas....

\begin{tabular}{c|c|c} 
PALAVRAS & FREQUENCIA & CATEGORIAS \\
\hline Água & 38 & 3 \\
\hline Estudo & 19 & 3 \\
\hline Sistema & 17 & 3 \\
\hline Reservatório & 13 & 3 \\
\hline Abastecimento & 10 & 5 \\
\hline Qualidade & 10 & 6 \\
\hline Uso & 08 & 6 \\
\hline Utilidade & 7 & 7 \\
\hline Resultado & 7 & 3 \\
\hline Chuva & 7 & 4 \\
\hline Processo & 7 & 4 \\
\hline Tratamento & 7 & 3 \\
\hline Mananciais & 7 & \\
\hline & & \\
\hline
\end{tabular}




\begin{tabular}{c|c|c} 
Capacidade & 6 & 3 \\
\hline Modelo & 6 & 2 \\
\hline Dados & 6 & 2
\end{tabular}

Fonte: elaborada pelos autores. 


\section{DISCUSSÕES}

Segue abaixo, as categorias temáticas elaboradas a partir da revisão bibliográfica sistemática.

\section{ATUAL SITUAÇÃO DO SISTEMA DE ABASTECIMENTO NO PAÍS}

Tendo em vista a atual dificuldade do sistema de abastecimento do país, é de suma importância criar meios que visem mitigar tais dificuldades, sendo por novas tecnologias, como também pela criação de políticas públicas que tenham como intuito estimular a reutilização ou a usabilidades de novos meios de abastecimento de água.

Porém, o fato é que nas atuais circunstâncias em que se encontra esse sistema no Brasil, isso ainda está longe por fatores que vão desde a falta de interesse por parte do governo, como também a falta de investimentos na área.

Atualmente cerca de 40 milhões de pessoas não tem acesso a esse serviço básico, o que retrata a precariedade desse sistema, enfatizando ainda mais a urgência de buscar soluções que amenizem a situação que afeta tantos brasileiros (PEREIRA, 2015).

\section{POTENCIAIS INOVAÇÕES PARA MITIGAR OS EFEITOS DO MAL ABASTECIMENTO NO PAÍS}

Partindo do pressuposto o caráter de urgência em mitigar os danos oriundos da má gestão dos recursos hídricos, temos como ênfase a reutilização e a busca por meios de se fazer o reaproveitamento da água, seja ela advinda das chuvas ou o próprio reaproveitamento da água para fins domésticos, como é o caso do dimensionamento de reservatórios que tenham recursos capazes de fazer o próprio tratamento prévio da água, através de fluoretação por exemplo ou de maneiras mais naturais como o uso de carvão com o intuito de realizar tal limpeza, tratado nos artigos 2 e 3 dessa revisão (REZENDE, 2016).

Outra maneira de se fazer uma boa gestão afim de corroborar com a distribuição correta dos recursos hídricos é através da criação de equipamentos capazes de gerir esses recursos, contudo, quanto mais efetivo for, mais oneroso fica indo de encontro a um dos principais problemas que impactam diretamente para a péssima situação de abastecimento de água no país, que é a falta de investimentos na área. Porém, há também a possibilidade de se fabricar equipamentos de baixo custo que beirem as finalidades propostas, como é o caso dos equipamentos MPR datalogger, tratados no artigo 6 dessa revisão, que tem como intuito monitorar informações como pressões hídricas das residências as quais o mesmo for instalado, trazendo dados como possíveis desperdícios por exemplo, levando a descoberta de falhas nos sistemas responsáveis pelo abastecimento de água daquela região (SILVA, 2015).

Entrando nesse mesmo mérito da análise de dados e do atual sistema de abastecimento de água, faz-se necessário fazer esse mapeamento, pois grande parte desse déficit no que diz respeito ao abastecimento, é em função do desconhecimento desses "pontos cegos" do sistema, onde por diversas vezes ali está concentrado o maior problema, logo análises computacionais são de grande valia quando se há a necessidade de fazer esse mapeamento. É o que propõe o artigo 8 dessa revisão, em que através da ferramenta SIMCAP, as informações principais do sistema são elucidadas. 
"A ferramenta SIMCAP foi desenvolvida de forma a gerar resultados sobre a garantia do abastecimento de um sistema de captação de água de chuva, a consequente redução do consumo de água da rede pública e a economia financeira equivalente à utilização dessa fonte para fins não potáveis. Assim, um dos principais aspectos positivos da utilização da ferramenta é a rapidez em se obter informações técnicas e econômicas relevantes à tomada de decisão. Outro benefício é que sua formulação pode ser editada por pessoas que saibam utilizar o software Excel. Dessa forma, além de ser passível de aprimoramentos, está acessível para uso geral (BRANDÃO, 2018)."

\section{PROGNÓSTICO PARA O FUTURO DO SISTEMA DE ABASTECIMENTO DE ÁGUA NO BRASIL}

Hoje a principal dificuldade no nosso sistema de abastecimento de água é fazer o correto manejo e gestão desses recursos, tendo isso em vista e sabendo da gravidade da situação, é visto com bons olhos a criação de maneiras sustentáveis e objetivas que visem mitigar esses danos, tendo justamente a correta gestão dos recursos como o principal objetivo. Aprimoramento das ETA's e ETE's, fabricação de equipamentos que façam análises de gestão do abastecimento como pressões hidráulicas e coisas dessa natureza são só alguns exemplos de artifícios já desenvolvidos para ajudar na resolução desse problema, contudo não tão disseminados como deveriam, tudo isso pelo fato de que faltam investimentos na área.

O fato é que o Brasil possui uma das maiores reservas de recursos hídricos do mundo, mas precisa saber gerenciá-la, afim de amenizar o problema que como já citado, afeta diretamente 40 milhões de brasileiros que não tem acesso a esse sistema. Para os próximos anos, a previsão é que a atual situação comece a melhorar, pois medidas como o "NOVO MARCO DO SANEAMENTO" (que visa mitigar a escassez do saneamento básico do país, que está ligado diretamente com o problema de abastecimento de água), já foi implantado no país, logo, isso nos leva a crer que o governo de fato está se movendo, ainda que não com os esforços que a princípio deveria, porém, dando certa prioridade ao problema.

\section{CONCLUSÃO}

De fato, nos encontramos em situação desconfortável quando falamos em abastecimento dos recursos hídricos, comparativamente estando inclusive atrás de países com menos recursos hídricos e econômicos, logo isso chegamos facilmente a conclusão que todo esse problema se dá pelo fato da má gestão e a estagnação dos atuais sistemas, que vão cada vez mais ficando arcaicos e ultrapassados.

Contudo, a boa notícia é que há maneiras de se reverter isso, a longo prazo, é verdade, mas existem, sendo que o principal imbróglio disso tudo é a falta de interesse e principalmente a falta de investimentos na área, haja vista que a medida que problemas não são solucionados hoje, tomam proporções maiores com o passar dos anos. Infelizmente esse problema não é concentrado em apenas uma região do país, mas sim em todo território nacional, o que implica dizer que é necessário e em caráter de urgência que os órgãos competentes tomem medidas afim de mitigar o caos gerado com a má gestão desses recursos. Planos de ações, sejam elas governamentais ou não, investimentos na área, monitoramento do atual sistema são maneiras a curto prazo que corroboram para isso, o que ainda não é o suficiente, mas já 
gera boas expectativas para a mitigação desse problema.

Outro ponto importantíssimo, porém, pouco difundido é que é preciso também fazer uma conscientização na população, haja vista que não adianta ter ótimas maneiras de gerenciar o abastecimento dos recursos hídricos se a própria população não fizer $\mathrm{o}$ manejo correto, tendo em vista a não reutilização em alguns casos como também o desperdício e o uso sem moderação.

\section{REFERÊNCIAS}

BRASIL. Lei $\mathbf{n}^{\mathbf{0}} \mathbf{1 2 3 1 8}$, de 26 de agosto de 2010. Dispõe sobre a alienação parental e altera o art. 236 da Lei no 8.069, de 13 de julho de 1990. Disponível em:

<http://www.planalto.gov.br/ccivil_03/_at o2007-2010/2010/lei/112318.htm>. Acesso em: 04 jan. 2020.

Assembleia Legislativa. Projeto de Lei do Senado $\mathbf{n}^{\mathbf{0}} \mathbf{7 0 0}$, de 2007. Altera a Lei $\mathrm{n}^{\circ}$ 8.069, de 13 de julho de 1990 (Estatuto da Criança e do Adolescente), para caracterizar o abandono afetivo como ilícito civil e penal e dá outras providências. Disponível em: http://tmp.mpce.mp.br/orgaos/CAOCC/dir Famila/projetolei/PL_700-2007.PDF. Acesso em: 08 jan. 2020.

FIORELLI, José Osmir; MANGINI, Rosana Cathya Ragazzoni. Psicologia jurídica. 4 ed. São Paulo: Atlas, 2012.

SILVA, Denise Maria Perissini da.

Psicologia jurídica no processo civil brasileiro: a interface da psicologia com o direito nas questões de família e infância. 3. ed. rev., atual. e ampl. Rio de Janeiro: Forense, 2016.
Percebe-se que é uma luta em conjunta, onde se faz necessário cada um fazer sua parte para que o atual sistema de abastecimento de água no país mude de patamar e deixe de ser um dos piores do continente, haja vista a grande quantidade de recursos hídricos que sem dúvida alguma possibilitam que as populações tenham acesso a um sistema de abastecimento minimamente digno.

SILVA, Liniker Douglas Lopes da; CHAPADEIRO, Cibele Alves; ASSUMPCAO, Marina Cunha. O exercício da parentalidade após a dissolução conjugal: uma revisão integrativa. Pensando fam., v. 23, n. 1, p. 105-120, jun. 2019. Disponível em $<$ http://pepsic.bvsalud.org/scielo.php?scrip $\mathrm{t}=$ sci_arttext\&pid=S1679494X2019000100009\&lng=pt\&nrm=iso $>$. Acessos em 07 jan. 2020.

CARVALHO, Rodrigo Delalibera et al.

Otimização do dimensionamento em sistemas de bombeamento fotovoltaico: validação de modelo em sistema piloto na comunidade rural de Rio Belo, Orleans (SC). Engenharia Sanitaria e Ambiental [online]. 2018, v. 23, n. 6 [Acessado 14 junho 2021], pp. 1153-1162. Disponível em: <https://doi.org/10.1590/S141341522018160134>. Epub 22 Out 2018. ISSN 1809-4457. https://doi.org/10.1590/S141341522018160134. 
REZENDE, Jozrael

Henriques e TECEDOR, Natália.

Aproveitamento de água de chuva de cobertura em edificações:

dimensionamento do reservatório pelos métodos descritos na NBR 15527. Revista Ambiente \& Água [online]. 2017, v. 12, n. 6 [Acessado 14 junho 2021], pp. 10401053. Disponível em:

<https://doi.org/10.4136/ambi-agua.1940>. Epub Nov-Dec 2017. ISSN 1980-993X.

BORGES, Rívea Medri et al. Uso de filtros de carvão ativado granular associado a microrganismos para remoção de fármacos no tratamento de água de abastecimento. Engenharia Sanitaria e Ambiental [online]. 2016, v. 21, n. 04 [Acessado 14 junho 2021], pp. 709720. Disponível em: $<$ https://doi.org/10.1590/S141341522016118787>. Epub 05 Set 2016. ISSN 1809-4457.

CRUZ, Nathalie e Mierzwa, José Carlos. Saúde pública e inovações tecnológicas para abastecimento público. Saúde e Sociedade [online]. v. 29, n. 1 [Acessado 14 junho 2021], e180824. Disponível em:

<https://doi.org/10.1590/S010412902020180824>. ISSN 1984-0470.

VENTURINI, Ceci Queluz et al.

Vigilância e monitoramento de fluoretos em águas de abastecimento público: uma revisão sistemática. Revista Ambiente \& Água [online]. 2016, v. 11, n. 4

[Acessado 14 Junho 2021] , pp. 972-988.

Disponível em:

<https://doi.org/10.4136/ambi-agua.1929>. Epub Oct-Dec 2016. ISSN 1980-993X.
BEREGULA, Renato Leandro e SILVA, Fernando Rodrigues. Equipamento de baixo custo para monitoramento de pressões em sistemas de abastecimento de água. Engenharia Sanitária e Ambiental [online]. 2020, v. 25, n. 6 [Acessado 14 junho 2021], pp. 809-820. Disponível em: <https://doi.org/10.1590/s141341522020192896>. Epub 23 Nov 2020. ISSN 1809-4457.

SONOBE, Henrique Gamon, LAMPARELLI, Marta Condé e CUNHA, Davi Gasparini Fernandes. Avaliação espacial e temporal de aspectos sanitários de reservatórios com captação de água para abastecimento em SP com ênfase em cianobactérias e cianotoxinas. Engenharia Sanitária e Ambiental [online]. 2019, v. 24, n. 05 [Acessado 14 junho 2021], pp. 909-918. Disponível em: $<$ https://doi.org/10.1590/S141341522019193351>. Epub 25 Nov 2019. ISSN 1809-4457.

BRANDÃO, João Luiz Boccia e MARCON, Priscila. SIMCAP: ferramenta computacional para auxiliar a tomada de decisão sobre a implantação de sistemas de captação de águas pluviais. Engenharia Sanitária e Ambiental [online]. 2018, v. 23, n. 6 [Acessado 14 junho 2021], pp. 1027-1030. Disponível em: <https://doi.org/10.1590/S141341522018129229>. Epub 08 Out 2018. ISSN 1809-4457. 
SALVINO, Moisés Menezes,

CARVALHO, Paulo Sergio Oliveira

de e Gomes, HEBER, Pimentel.

Calibração multivariada de redes de

abastecimento de água via algoritmo

genético multiobjetivo. Engenharia

Sanitaria e Ambiental [online]. 2015, v. 20,

n. 03 [Acessado 14 junho 2021], pp. 503-

512. Disponível em:

$<$ https://doi.org/10.1590/S1413-

41522015020000099484>. ISSN 1413-

4152. 